\title{
Realismo às avessas: $o$ estilo impressionista de Adelino Magalhães
}

\section{Stela de Castro Bichuette*}

\begin{abstract}
Resumo: Ao estudar o estilo impressionista na prosa de ficção percebeu-se as confluências e muitos pontos de contato entre esse estilo e o Realismo, embora, a princípio, se pareçam processos tão díspares. Este trabalho procura especificar a proximidade entre ambos, mostrando o tratamento dado ao objeto no Impressionismo e no Realismo. Procurar-se-á essa especificação dada ao tratamento do objeto através do objeto-coisa,, no caso do Realismo, e do objeto-tema no caso do Impressionismo, enfocando estes aspectos na obra de Adelino Magalhães (1887-1969).
\end{abstract}

Palavras-chave: Impressionismo; Realismo; Adelino Magalhães

\begin{abstract}
The present article sets its starting point on the studying of the impressionism style in literature in order to understand the convergence and many contact points between this style and Realism style, although, a priori, both schools seem to have different processes of construction. This work seeks to specify the proximity between them, showing the treatment given to the object by each one. To make the discussion we have considered the treatment of the object: in the case of Realism, object-thing, and in the Impressionism, object-subject, focusing Adelino Magalhães (1887-1969) works.
\end{abstract}

Keywords: Impressionism; Realism; Adelino Magalhães

As primeiras manifestações impressionistas surgem na pintura francesa na segunda metade do século XIX, enquanto na literatura ainda predominava a escola realista-naturalista. Enquanto as novas técnicas de aproveitamento da luz usadas pelos pintores impressionistas permitem que estes se distingam de seus antecessores com nitidez, na esfera das letras a distinção não é tão fácil de se fazer. Ao componente impressionista na dimensão literária se ajuntam várias vertentes; fala-se na confluência entre fenômenos simbolistas e realistas.

Cronologicamente, também existe certo desencontro entre o impressionismo em literatura e o impressionismo em pintura; o período mais fecundo do impressionismo em pintura já passara quando as suas características de estilo começam a desenhar-se na literatura. (HAUSER, 1972, p.1058)

No sentido mais amplo e tradicional, o movimento pictórico impressionista é definido "como uma tentativa inédita para apreender a realidade da luz fazendo disso o principal, senão o único, objectivo da pintura.” (FRANCASTEL, 1972, p.17)

\footnotetext{
* Mestre em Letras - Estudos Literários pela Universidade Estadual de Londrina. Doutoranda em Letras Estudos Literários, pela mesma universidade.
} 
No entanto, o historiador de arte Pierre Francastel (1998) argumenta que essa definição é muito rasa se comparada com o que os primeiros pintores impressionistas realmente tinham em mente. Francastel explica que Monet queria menos uma transformação de ordem técnica do que a vontade de transmitir efeitos novos. O historiador também explica que quando o pintor teve as primeiras ideias sobre as Nymphéas ele não pretendia:

realizar uma obra de habilidade em que a composição clássica tenderá a dissolver-se, em que o artista agarrará o reflexo das coisas e não dos objetos, em que os tons divididos figurarão a constituição da luz, mas sim que quer pintar "qualquer coisa de impossível, água com ervas que ondulam sob raios de sol" O ponto de partida das suas investigações, o ponto de vista a que se reporta para julgar o valor dos seus ensaios é, sem dúvida nenhuma, sentimental (FRANCASTEL, 1998, p.117).

Um outro importante argumento de Pierre Francastel (1998) quanto a não ser a técnica impressionista apenas uma nova maneira de os pintores tratarem a luz diz respeito ao espaço e ao tempo em que viviam aqueles artistas. O historiador de arte afirma a necessidade daqueles artistas de retratar as influências provocadas pelo ambiente histórico e social que eles, os pintores, compartilhavam junto aos poetas, intelectuais e filósofos. Com isso, Francastel quer dizer que não é por um passe de mágica que o artista produz um novo procedimento artístico, mas que "os artistas inserem-se na atitude geral da época em que vivem, tanto pelo modo como entendem o objetivo da arte como, e sobretudo, pelo seu método de trabalho" (FRANCASTEL, 1998, p.114).

Devido à ascendência do contexto social sobre os artistas de um período, Francastel insiste "na impossibilidade absoluta de limitar a um comentário técnico o estudo de uma época, cheia de complexas aspirações, que pôs em causa, sob todos os aspectos, a própria noção da arte de pintar" (FRANCASTEL, 1998, p.119).

É o que acontece, por exemplo, com Manet, que sofre influência de Baudelaire. Segundo Francastel, "toda uma parte da obra de Manet se explica pela vontade sistemática de rejuvenescer os valores estabelecidos" (FRANCASTEL, 1998, p.115). Comparando essa afirmação com a crítica de arte de Baudelaire, não parece errôneo verificar uma concordância de ideias:

Sem dúvida, é excelente estudar os antigos mestres para aprender a pintar, mas isso pode ser tão-somente um exercício supérfluo se o nosso objetivo é compreender o caráter da beleza atual. [...] Em poucas palavras, para que a Modernidade seja digna de tornar Antigüidade, é necessário que dela se extraia a beleza misteriosa que a vida humana involuntariamente lhe confere (BAUDELAIRE, 2002, p.26).

Nesse sentido, a influência de Baudelaire sobre os pintores como Manet é visível. A conclusão feita por Francastel acerca dessa assertiva encontra-se na seguinte passagem: 
Não há dúvida de que aqui [Bar aux Foles-bergères, de Manet] há uma admirável naturezamorta, não há dúvida de que é mais do que uma versão realista e modernizada do tema da criadinha ou da leiteira, popularizado pela gravura; é um estudo directo de costumes em que transparece a nota sentimental (FRANCASTEL, 1998, p.116).

A correspondência entre os dois artistas franceses fica ainda mais próxima quando Francastel comenta, novamente, o estudo de Bar aux Folies-bergères feito por M. Paul Janot. No quadro há o momento prático subtraído do mundo real e a associação de ideias e cores. É o que mais tarde os escritores impressionistas farão na literatura: incorporarão a realidade objetiva dos realistas-naturalistas e a representarão por influência das sensações instigadas por essa realidade.

A manifestação do dinamismo e da mudança constante é descrita por Baudelaire como características do tempo moderno; para ele, a modernidade é o efêmero e o transitório. Assim, os artistas devem manter-se atentos à capacidade de extrairem do presente mutante o eterno e o imutável — tal intuito somente poderá ser alcançado através do rejuvenescimento dos temas. É nesse sentido que a professora Jeanne Marie Gagnebin (1994) afirma que "Baudelaire defende uma visão positiva da arte moderna e da modernidade em oposição à concepção acadêmica e tradicional do Belo como forma eterna e absoluta" (GAGNEBIN, 1994, p.55), diz ainda:

o novo está, por definição, destinado a transformar-se no seu contrário, no não mais novo, no obsoleto e no envelhecido, então o moderno designa um espaço de atualidade cada vez mais restrito. Em outros termos, a linha de demarcação, outrora tão clara entre o moderno e o antigo, tende a apagar-se, pois o moderno se transforma cada vez mais rapidamente em seu contrário. Ao se definir como novidade, a modernidade adquire uma característica que, ao mesmo tempo, a constitui e a destrói (GAGNEBIN, 1998, p.56).

A representação da argumentação de Baudelaire se faz presente na sua concepção de Belo. Quanto à obra-de-arte, a respeito da pintura, Baudelaire fala no estudo que "não temos o direito de desprezar ou de prescindir desse elemento transitório fugidio, cujas metamorfoses são tão freqüentes. Suprindo-os, caímos forçosamente no vazio de uma beleza abstrata e indefinível (...)" (BAUDELAIRE, 2002, p.26). Sobre esse ponto, o filósofo contemporâneo Jürgen Habermas, ao discutir a obra de Baudelaire, argumenta:

a obra autêntica está radicalmente presa ao momento em que nasce; exactamente porque se consome na actualidade é que pode deter o fluxo regular das trivialidades, romper a normalidade e saciar por um momento, o momento da efêmera fusão do eterno com o actual, o imortal anseio de beleza (HABERMAS, 1998, p.21). 
Seguindo-se a linha de pensamento de Baudelaire tem-se que, para o poeta francês, o Belo é constituído por um elemento eterno e por outro relativo, variável. Este último seria a época, a moral, a paixão. Baudelaire afirma: “A dualidade da arte é uma conseqüência fatal da dualidade do homem. Considerem, se isso, lhes apraz, a parte eternamente subsistente como a alma da arte, é o elemento variável como seu corpo" (BAUDELAIRE, 2002, p.11).

Em razão disso, o que a arte impressionista quer retratar é a experiência interna que o mundo provoca no espírito do artista. E será a vida urbana das grandes cidades o espaço preferencial para os impressionistas. A natureza é negada como tema para esses poetas e a cultura citadina é o que procuram esses escritores.

O Impressionismo é uma arte urbana, e o é não só porque descobre a qualidade paisagística da cidade, e faz regressar a ela a pintura dos campos, mas também vê o mundo pelos olhos do citadino e reage às impressões internas com os nervos tensos do moderno homem técnico. É um estilo urbano porque descreve a mutabilidade, o ritmo nervoso, as impressões súbitas, pungentes, mas sempre efêmeras da vida das cidades (HAUSER, 1972, p.1049).

Assim, diante do exposto, mais uma vez evidencia-se a influência de Baudelaire nos pintores e escritores impressionistas. Para ele, o homem em seu estado natural é apenas um ser animalesco, e a natureza é voz de seus interesses.

O crime, cujo gosto animal humano hauriu do ventre da mãe, é originalmente natural. A virtude, ao contrário, é artificial, sobrenatural, já que fora necessários, em todas as épocas e em todas as nações, deuses e profetas para ensiná-la à humanidade animalizada, que o homem por si só, teria sido incapaz de descobri-la. (BAUDELAIRE, 2002, p.57).

Baudelaire afirma, ao contrário de Rousseau, que o mal é natural ao homem. Por outro lado, tudo que é belo e nobre, aqui se pode incluir a moral e a ética, é fruto da razão e do cálculo. Fica claro, neste momento, a oposição das palavras usadas pelo poeta no título do conjunto mais famoso de seus versos - Flores do Mal.

Diferentemente do que ocorre na pintura, no período literário de fim de século e começo de século XX, não é tão cômoda a separação entre os diversos estilos literários em voga, uma vez que eles coexistiam. Afrânio Coutinho (1969) já aponta, n’A Literatura no Brasil, para a dificuldade de separar e identificar os estilos da literatura da época, pois são vários os motivos que se misturam e se confundem e que o "quadro da literatura na passagem do século mostra o Impressionismo como herdeiro e continuador do Realismo; o Simbolismo, prolongamento do Romantismo; o Parnasianismo, expressão do Realismo-Naturalismo na poesia" (COUTINHO, 1969, p.17). Afrânio Coutinho avalia que a transformação que se deu na literatura brasileira entre o fim do século XIX e começo do século XX é resultado da união 
do Simbolismo com o Naturalismo, vindo a produzir a corrente impressionista que por sua vez influenciaria, posteriormente, a gênese do Modernismo.

Um outro nome a compartilhar dessa afirmação é Xavier Placer (1962), que explica:

o Impressionismo aponta vagamente nos primórdios do Novecentos, na ficção saturada de pathos do Romantismo; depois, por volta do meado de século, o veio se avoluma no frisson nouveau dos poetas precursores do Simbolismo, assim como na prosa emotiva dos romancistas realistas e naturalistas, para ir, já nas últimas décadas, desaguar no Simbolismo. - Aí, por afinidades sutis, amalga-se com a escola vitoriosa, que o suplanta. Com o advento do século $\mathrm{XX}$, ao passo que o Simbolismo entra em recesso e passa a influir subterraneamente. $\mathrm{O}$ Impressionismo - valor original temperado por aquelas influências - singulariza-se, dando uma arte característica, que era simultaneamente transição para o Modernismo (PLACER, 1962, p.13).

No início do século XX, o entrecruzamento de tendências artísticas foi muito forte. O Simbolismo fica ofuscado pelo sucesso brasileiro do Parnasianismo; no entanto, ambos conviviam paralelamente e muitas vezes se misturavam nas produções artísticas do período, confirmando as mudanças que vinham se processando no campo das letras.

Era esta a atmosfera espiritual; pelo menos no centro cultural mais importante, o Rio de Janeiro. O Símbolo expirante cedia a favor de uma pesquisa de caráter personalíssimo levada a efeito por parte dos "novos" do tempo, na tentativa de fazer diferentes daquela conquistas já cristalizadas e formais da Escola. Abandonava-se o Símbolo e as maiúsculas, a teoria das correspondências das cores e outra, para dar lugar à Impressão, mensagem pessoal da realidade captada através dos sentidos e analiticamente decomposta em seus elementos. É assim que, sem forçar interpretações, pode-se assinalar, tanto no estrangeiro como aqui, um Impressionismo de primeira hora: exterior, descritivo; um de segunda fase: psicológico, onde o monólogo interior representa magna parte (PLACER, 1962, p.19).

O sucesso e a aceitação do Simbolismo no Brasil foram bem modestos. Tal movimento, entretanto, foi valorizado posteriormente pelas gerações seguintes aos modernistas. A má recepção pela crítica da obra Broquéis, de Cruz e Souza, demonstra bem essa situação. Ivan Teixeira questiona o que

tinha Broquéis de tão diferente para merecer toda aquela incompreensão crítica, quando não uma enorme desconsideração social, que se infiltrou em ostensivas murmurações pelos cafés e rodas literárias da época? Primeiro, o livro introduzia no Brasil a poesia pura, marcada pelo deliberado abandono de significado explícito e pelo apego à sugestão insinuante (TEIXEIRA, 1994, p.XII).

A relação de Adelino Magalhães com os poetas simbolistas brasileiros é muito próxima. Não poderia ser muito diferente, uma vez que a reação espiritualista, na qual Magalhães é também lembrado, emerge, sobretudo, da ligação poética com a veia simbolista. Segundo Sílvio Castro (1979), em Teoria e Política no Modernismo brasileiro, o simbolista Cruz e Souza tem um importante papel nas pesquisas poéticas do grupo carioca modernista. O surgimento de Manuel Bandeira, com Cinza das Horas em 1917 - ano também da estreia de 
Mário de Andrade com Há uma gota de sangue em cada poema - confirma a revolução da poesia iniciada pelo Simbolismo.

Não é coerente negar que a linguagem obscura e cheia de metáforas da escola simbolista se mantém viva na prosa de Adelino Magalhães.

No setor da prosa esta revolução encontrava seu correspondente em Adelino Magalhães. Quando apareceram Casos e Impressões em 1916, a prosa de ficção toma uma direção revolucionária. Revolucionária pelo uso de uma linguagem impressionista - herdada dos prenúncios melhores de Raul Pompéia - e como ato de ruptura em relação à tradição formalista nacional. A língua de Adelino Magalhães é proposta aberta em direção da prosa artística sem limitações expressivas, livres de uma estrutura formal inibitiva e capaz de ampla expressividade. Uma língua que segue as linhas prenunciadas pela pesquisa simbolista no plano lingüístico, pesquisa que já conduzira Cruz e Sousa a uma prosa-poesia capaz de realizar os primeiros saltos em uma direção metafórica tal que quase consegue neutralizar positivamente a condição metonímica da recorrência parnasiano-realista Essa pesquisa simbolista por uma nova língua literária abre as perspectivas largas de Raul Pompéia, que na luta corpórea com a antiga, tradicionalista e reacionária, trabalhando principalmente na suas Canções sem metro, consegue habilitar a prosa de ficção brasileira de uma linguagem inédita. A nascente linguagem impressionista conquista contornos estáveis justamente com a prosa de Adelino Magalhães (CASTRO, 1972, p.122).

Na fusão dos elementos simbolistas, naturalistas e realistas, os impressionistas, movidos pela maneira de focar a realidade pelas reações idealistas provindas do fim do século XIX, preocupam-se não mais com o objeto em si, objeto-coisa, mas com as sensações e emoções que irradiam desse mesmo objeto no espírito do artista, fazendo com que o objeto passe a ser tratado como tema de sua arte.

O escritor impressionista lida com os estados de alma e, por isso, o enredo fica atrelado a esses momentos. O que é levado em consideração passa a ser a necessidade de expressão daqueles momentos introspectivos que o escritor quer evidenciar tão fielmente. $\mathrm{O}$ tratamento dado a esse tipo de narrativa privilegia não mais a descrição realista e objetiva das coisas tangíveis, mas sim a retratação precisa das emoções provocadas no espírito das personagens por esses fatos. $\mathrm{O}$ autor deseja que o leitor compartilhe as impressões proporcionadas pelo mundo objetivo a fim de que o mesmo experimente a sensação proveniente de uma determinada situação como se a estivesse vivenciando.

Dessa forma, a gênese do pensamento impressionista na prosa literária se firma por dois pontos: o Realismo-Naturalismo de um lado e o Simbolismo de outro. Do contato com o Realismo provém a objetividade, uma vez que realistas e impressionistas são precisos — os primeiros o são ao retratar as coisas; os segundos, sendo fiéis ao representar suas emoções. De acordo com Jean Beverly Gibbs (1952), isso se dá porque

Therefore, contrary to realism, in impressionism, there is an element which is entirely subjective, and this element is the sensation itself [...] There is always something in this sensation which is unconsciously an interior quality of the artist, and in this respect 
individuality or subjectivity is evidenced in impressionism, whereas it is excluded from realism and naturalism (GIBBS, 1952, p.176).

Por este viés, há semelhança de ideias entre Gibbs e Hauser - o segundo questiona qual tendência substituirá a escola naturalista, quase já em seu fim, visto que nas raízes da corrente subjetiva permanecia, ainda que de uma forma bastante tênue, a objetividade de retratar as emoções. Sobre isso Hauser sugere:

Que era, acima de tudo, o "romance psicológico" de Boourget, Barrès, Huysmanas e mesmo Proust senão o resultado da observação interessada pelo "documento humano"? E que é, em última análise, todo romance moderno, senão a descrição pormenorizada e cada vez mais precisa da concreta realidade espiritual? É perfeitamente verdade que certas características antinaturalistas estão todas inseparavelmente ligadas ao impressionismo em literatura, como em pintura, mas ainda estas rompem do solo do naturalismo (HAUSER, 1972, p.1060-1061, grifo meu).

O destaque dado por Gibbs a respeito do tratamento dos objetos extraídos da realidade, tanto no Realismo-Naturalismo quanto no Impressionismo, pode ser pensado mediante a retratação fiel dos assuntos por ambas as escolas. Assim, Gibbs sustenta a tese de que tanto os realistas quanto os impressionistas são objetivos. A diferença está em como se dá essa objetividade, ou seja, os impressionistas tratam seus objetos como tema, que são as sensações; já os realistas retratam seus objetos como coisas representando-as fielmente sem deixar de fora nenhum detalhe, tal qual se apresentam no mundo material.

In the case of impressionism an object is necessarily involved which acts as a stimulus in order to produce the sensation which the observer receives. In other words, as it appears to me, the external world is, figuratively speaking, imposed upon the receptor, which in this case is the artist (GIBBS, 1952, p.177).

Gibbs afirma que a visão dos autores realistas acerca da retratação da realidade, que é a experiência objetiva do mundo, vai ser oposta por um novo caminho - o Impressionismo. Conhecido como uma corrente puramente subjetiva, o Impressionismo, nessa perspectiva, tem sua gênese na visão objetiva apresentada pelo Realismo e Naturalismo. O que o Realismo e o Impressionismo têm em comum é um proposto exato de representação. O Realismo quer retratar o mundo assim como ele é, já o Impressionismo tem a pretensão de retratar detalhadamente as emoções provocadas pela realidade objetiva.

In realism, the whole object is carefully observed in all its detail, if the artist succeeds, the result will be an exact replica of the original. In impressionism, the observation is, shall we say, of shorter - it is a "vistazo", a flash perception of an outstanding aspect, and the sensation gained from this instantaneous perception is reproduced just as carefully and in just as great detail as is the total object of the realist (GIBBS, 1952, p.175-176).

A visão estática do mundo é contraposta pelo dinamismo do tempo; em um mundo onde os fenômenos estão em fluxo, a realidade passa a ser um eterno devir. O momento 
fugaz, a transitoriedade é trazida para o conhecimento público pelos pintores através da fragmentação e da descontinuidade. Assim como os pintores na pintura, os escritores impressionistas representarão as impressões da experiência do tempo em movimento constante através da realidade objetiva, que se transfigurará em virtude da sua percepção pelos órgãos do sentido. Pierre Francastel apresenta a seguinte afirmação sobre o assunto:

Para Manet, Pissaro e os seus contemporâneos, a natureza não é uma matéria de reflexão, mas uma fonte imediata de sensações puras. Assim, o que há neles de inovador, não tanto a própria prática da pintura ao ar livre, mas mais o seu método de trabalho. Renunciam às preparações tradicionais e à habitual visão das formas, das luzes e do motivo. Substituem-nas por um método em que o imaginário tem sempre um papel a desempenhar, por um trabalho de fixação dos puros dados do sentido, ou para ser mais exato exclusivamente do sentido óptico (FRANCASTEL, 1998, p.21).

Assim, a perspectiva se deslocará do objeto estático para um mundo caracterizado pelo fluxo contínuo do tempo e despirá a imagem de uma aparente uniformidade aumentando a percepção do mundo atomizado e cheio de dinamismo - o que pode ser perfeitamente percebido através das pinceladas rápidas e dos tremores das pontuações nas cores do quadro.

O impressionismo não só reduz a realidade a uma superfície de duas dimensões, mas dentro dessa bidimensionalidade, a um sistema de manchas informes; em outras palavras, omite não só a qualidade plástica, mas também o desenho, não só a forma espacial mas também a forma linear. Que o quadro ganha em energia e em encanto sensual o que perde em claridade e evidência é óbvio, e esse ganho é o que principalmente preocupa os próprios impressionistas (HAUSER, 1972, p.1054).

O contato dos impressionistas com os simbolistas é mais complexo e mais difícil de ser diferençado]. Os simbolistas inspiram os impressionistas pelo seu idealismo, pelas suas atitudes anti-racionais, pela negação das correntes cientificistas e técnicas e, como se viu, pela reação ao Parnasianismo e ao Naturalismo. O distanciamento entre Impressionismo e Simbolismo, no entanto, concretiza-se pela visão neoplatônica do Simbolismo, segundo a qual só é real aquilo que é refletido na consciência, enquanto o Impressionismo não busca desvincular-se da matéria. Para o impressionista, o indivíduo é composto por partículas e átomos. Há uma existência real e tocável que é percebida pelos órgãos dos sentidos.

Disso resultará o princípio do instantâneo sobre a continuidade do tempo. A arte incorporará o momentâneo pelas impressões do fato no homem. A importância não recairá mais no objeto, mas naquilo que ele provoca nos indivíduos. Há aqui maior valorização das emoções do que do objeto propriamente dito, maior importância da consequência de uma impressão do que particularmente sua causa. Na literatura, desaparece quase totalmente a intriga, e a atenção se volta aos estados de espírito. Ou como argumenta Hauser: 
O indeciso, o vago, o que existe nos limites mínimos da percepção dos sentidos passam a ser o tema principal da poesia; mas não é a realidade objetiva o que ocupa os poetas, mas as suas emoções acerca da sua própria sensibilidade e capacidade de sentir. Esta arte insubstancial de estados de espírito e de atmosfera domina todas a formas de literatura; todas elas se transformaram em lirismo, em imaginária e música, em timbres e tonalidades. A história que se conta reduz-se a meras situações, o entrecho a cenas líricas, o desenho das personagens à descrição as tendências e orientações espirituais. Tudo passa a ser episódico, periférico a uma vida sem alvo (HAUSER, 1972, p.1110).

A pintura também enfatiza a mobilidade do tempo e a reciprocidade do homem com seu fluxo contínuo do devir. A visão impressionista de mundo é calcada no papel que o tempo ininterrupto exerce sobre os seres no mundo. A crítica a respeito dessa estética volta os olhos para a tese defendida pelo filósofo pré-socrático Heráclito, para quem um homem não mergulha duas vezes no mesmo rio e, caso o faça, nem ele nem o rio serão os mesmos. A experiência se modifica com o passar do tempo e o indivíduo é a soma dessas experiências. "O presente é o resultado do passado, daí a necessidade de recordar, viver, reviver, ressuscitar o passado perdido" (COUTINHO, 1969, p.14). O tempo é o núcleo da célula impressionista.

As transformações contínuas da vida dos indivíduos e das sociedades em que estão inseridos ganham relevo na prosa impressionista. O momento presente do homem é retirado do perpetuum continuum em que vive para logo ser legado ao passado. É por esse motivo que o papel da memória se torna indispensável para a produção impressionista. De acordo com Hauser, isso se dá porque:

A existência adquire verdadeira vida, movimento, cor, uma transparência ideal e um conteúdo espiritual à custa da perspectiva de um presente que é resultado o nosso passado. Não há outra felicidade senão a de recordar e do reviver, da ressurreição e conquistas do tempo que passou e se perdeu; porque, como diz Proust, os verdadeiros paraísos são os paraísos perdidos (HAUSER, 1972, p.1112).

Será através da filosofia de Henri Bergson que o pensar impressionista terá sua expressão. Para Bergson, o espírito passa do passado ao presente e ao futuro, ininterruptamente, e o trabalho da consciência reside em escolher os momentos da experiência colhidos pela memória. ${ }^{1}$ Em Casos e Impressões, Adelino Magalhães elucida bem o peso do tempo sobre o homem, principalmente nas questões referentes às situações vividas pelas personagens. As personagens de Adelino Magalhães revivem suas recordações através das memórias de um tempo passado.

A memória, a rememoração dos fatos vividos, é o diferencial racional que os seres humanos possuem. Esta capacidade será levada ao extremo nos contos de Adelino Magalhães,

\footnotetext{
${ }^{1}$ Cf. GONÇALVES, Denise Mafra. Adelino Magalhães e a consciência do instante. Dissertação de Mestrado. Universidade de Brasília, 1990.(in mimeo) Neste trabalho, a autora analisa alguns contos de Adelino Magalhães através da filosofia de Henri Bergson.
} 
com suas personagens mergulhadas em recordações e lembranças. Será esse modo particular de ver o mundo a substância basilar das duas últimas partes de Casos e Impressões, a saber, "Casos de Criança” e "Casos e Impressões". É pela percepção da imagem material e objetiva que as impressões se fixarão no íntimo das personagens.

Na história de "João Amazonas", inserido na última parte de Casos e Impressões, pode-se perceber a suspensão do tempo cronológico e o trabalho da memória em resgatar algo de um passado adormecido. Veja-se um trecho do conto em que a realidade objetiva é abafada e começa para a personagem a lembrança do amigo morto:

— "Mas de que é que você está rindo?"

- "De nada..." Osvaldo olhou para mim, com uns longínquos fogos de despeito nas pupilas; esticou os beiços para toda a insignificância dos meus segredos e virando o pescoço, com donairosa vagareza, berrou:

— "Ó chefe, traz aqui mais um, escuro!"

Eu me pus a pensar no que Osvaldo contara e no que comentavam, ao meu lado, os dois outros rapazes que sorriam, ao mesmo tempo, inclinados um para o outro...

Tratava-se do Amazonas, que um dia se sumira da "roda": e de cuja existência vinha-nos então, pela boca do Osvaldo, o último eco junto ao brilho fulvo dos chopes, entre a algazarra luminosa e cantante do bar. (MAGALHÃES, 1963, p.177)

Após esse trecho, a personagem reconstruirá em sua lembrança o passado de amizade com Amazonas. Algumas vezes, durante as rememorações, a personagem é chamada de volta à realidade objetiva por Osvaldo, que quer saber em que o outro pensa. Isto ocorre para que a personagem não perca o contato com o mundo material e com as impressões não só do passado, mas também de sua realidade imediata. Dessa forma, mesmo com uma narração intimista, o conto se perde apenas nas divagações, ou seja, o leitor percebe de onde partem os devaneios da personagem central.

A apreensão do momento vivido terá sua representação através das experiências sensoriais. A grande maioria do conjunto de Casos e Impressões está intimamente ligada às sensações captadas pelos órgãos do sentido, isto é, à percepção individual das personagens da realidade material e à interiorização do momento, construindo uma releitura dessa mesma realidade através da sensibilidade.

Tudo isso estará imediatamente correlacionado com o desencadear do momento vivenciado, daquele particular momento que ao escritor serve de centro, para a fixação das impressões altamente subjetivas. Sobre isso, lança-se mão das reflexões de Norbert Elias que explica:

A memória desempenha um papel decisivo nesse tipo de representação, que enxerga em conjunto aquilo que não produz num mesmo momento. Ao falar dessa maneira numa capacidade de síntese, pretendo referir-me, em particular, àquela capacidade, característica do 
homem, de presentificar para si o que de fato não está presente hic et nunc, e de ligá-lo com o que está efetivamente presente hic et nunc (ELIAS, 1998, p.61).

A desintegração da realidade e a impressão de nebulosidade ao olhar um quadro impressionista é causada pelas omissões voluntárias que dão prioridade não mais ao motivo, mas às tonalidades. Na prosa, o relevo ao momento único e ao instante passageiro e rápido é o que marcará a narrativa do universo fragmentado que caracterizou os primeiros anos do século passado.

Tudo que é simples e claro, instintivo e sem requinte perde o seu valor; a capacidade de percepção, o intelectualismo e o que há de não-natural na cultura, eis o que se busca com fervor. Inteligência e as funções da faculdade crítica são também consideradas essenciais no processo de criação artística (HAUSER, 1972, p.1064).

Essa característica dificultará, vez ou outra, a percepção do recorte em Adelino Magalhães, tantos são os movimentos da memória em torno do passado, do presente e da projeção do futuro. No entanto, seria infundado negar que o recorte está muito bem delimitado, principalmente na percepção da personagem de seu entorno material em suas constantes idas e vindas ao/do passado.

Os questionamentos existenciais da época são resultado do abalo na concepção de mundo sofrido pelos homens desse fim de século XIX e início de século XX, principalmente no que tange a confiança depositada na ordem científica e técnica. Neste contexto, a relativização e psicologização da narrativa também são motivadas pelas teorias da memória e inconsciente. Afrânio Coutinho explica que "a superioridade da 'civilização', no sentido otimista e absoluto em que foi concebida pelo Iluminismo e Progressismo do século XIX, também decepcionou, e, na palavra de Paul Valéry, verificou-se que as civilizações também eram mortais" (COUTINHO, 1969, p.27).

Esse modo particular de ver a realidade se traduz nos temas dos contos de Adelino Magalhães. Será o predomínio da introspecção e do estado de espírito sobre a intriga. O resultado é, de acordo com Hauser, a eliminação progressiva do que se conta. Veja:

Toda a arte do período manifesta uma tendência para o psicológico e o lírico, e a fuga da "história", a substituição do movimento externo pelo interno, da intriga por uma filosofia e interpretação da vida, tudo isso se pode considerar o caráter da nova orientação da arte que por toda parte está a evidenciar-se (HAUSER, 1972, p.1100).

A captação da fugacidade da vida e do movimento transitivo do homem no mundo, “sempre viajando através do grande deserto de homens" (BAUDELAIRE, 2002, p.24), é um dos pontos de partida do estilo impressionista. Tudo que era estável será representado mediante as sensações ópticas. Pode-se dizer que tanto na pintura quanto na literatura 
impressionista a realidade será flutuante, pois os objetos estão em constante indecisão e mutação.

Na perspectiva de Arnold Hauser, é no sentimento de rapidez e de variação que o impressionismo encontra sua expressão. Porque, diz ele,

A substituição constante e rápida de artigos de uso comum por outros novos leva, porém, a uma quebra no apreço pelos bens materiais e também, não tarda, pelos bens intelectuais, reajustar a rapidez com que se sucedem se revalorizações filosóficas e artísticas à das mudanças da moda. A técnica moderna introduz, assim, na atitude perante a vida um dinamismo sem precedentes (HAUSER, 1972, p.1049).

O escritor Adelino Magalhães estará mais próximo das técnicas narrativas impressionistas do que de outros "-ismos" que surgem com os movimentos de vanguarda. O autor foi classificado como antecipador, no Brasil, de vários desses “-ismos”, como se poderá verificar nos estudos críticos sobre sua obra.

Ao rever a temática escolhida por Adelino Magalhães nos contos de Casos $e$ Impressões percebe-se que a homogeneidade temática da cidade como espaço preferencial para as angústias do homem sugere a presença do homem urbano envolto em seus problemas morais, e por vezes até éticos, na sua construção interior. O desenvolvimento da cidade do Rio de Janeiro, que o escritor nomeia de Sebastianópolis, com suas luzes e seu dinamismo modernizante, são pontos-chave nos quais Adelino Magalhães ajusta a rapidez das relações com as impressões causadas nos personagens por essas relações passageiras. Dessa forma, pode-se recorrer mais uma vez ao poeta Baudelaire, para o qual "a cidade não é mais um simples lugar de passagem em oposição à estabilidade da cidade divina, mas o palco isolado de um teatro profano onde a destruição acaba por vencer sempre" (GAGNEBIN, 1994, p.58).

Além das imagens ligadas ao sentido visual, outro sentido encontra-se presente nos contos de Adelino: a audição. Os ecos onomatopeicos presentes dentro das narrativas são traços marcantes que se espalham por grande parte da obra do contista. Tais barulhos, bem como as imagens, refletem a angústia das personagens, fazendo com que questões do subconsciente comecem a se iluminar nas lembranças e reminiscências das mesmas.

Através deste recurso estilístico, o escritor consegue penetrar na consciência das personagens e retratar o momento degradante pelo qual as mesmas passam. Assim, os barulhos ajudam na elaboração da atmosfera dos contos. A percepção desses ecos torna possível reconhecer o momento desencadeador do devaneio em que a realidade objetiva é vedada, configurando-se na narrativa apenas a subjetividade das personagens. São tiquetaques de relógios, gotejos de chuva, buzinas de caminhões, ruídos de animais, que na construção dos contos alicerçam a composição do ambiente onde se misturam cheiros, sons e imagens. É 
importante, através deste ângulo, ressaltar que os barulhos e as imagens na produção de Adelino Magalhães despertam no texto um prolongamento das marteladas infrapsicológicas originadas na inconsciência das personagens.

Os barulhos e visões momentâneas da vida são percebidos pelas personagens e compor-se-ão em um universo ainda maior ao serem questionadas as misérias do ser, as angústias e a moralidade humana. $\mathrm{O}$ escritor consegue estruturar seus objetivos - levar às últimas consequências o pensamento das personagens — por meio de uma linguagem original e esteticamente em comunhão com o modelo impressionista sobre o qual se vem falando.

Assim o tempo se torna peça fundamental para o escritor impressionista, na fusão que se dá entre o tempo interno de um acontecimento e sua relação com o devir no fluxo do tempo contínuo. Em outras palavras, o impressionista coloca sua perspectiva em um acidente particular, em um instantâneo da vida; no entanto, o acontecimento fixado estará dentro do estado de fluxo temporal ininterrupto da vida dos indivíduos.

\section{Referências}

BAUDELAIRE, Charles. Sobre a Modernidade. O pintor da vida moderna . $3^{\mathrm{a}}$ edição. São Paulo: Paz e Terra, 2002.

CASTRO, Silvio. Teoria e Política do Modernismo Brasileiro. Petrópolis:Vozes, 1979.

COUTINHO, Afrânio. A Literatura no Brasil. Volume IV. Rio de Janeiro: Sul Americana S.A, 1969.

ELIAS, Norbert. Sobre o Tempo. Tradução: Vera Ribeiro. Rio de Janeiro: Jorge Zahar Editora, 1998.

FRANCASTEL, Pierre. O Impressionismo. Tradução de Maria do Sameiro Mendonça e Rosa Carreira. São Paulo: Martins Fontes, 1998.

GAGNEBIN, Jeanne Marie. História e Narração em W. Benjamin. São Paulo: Perspectiva: FAPESP: Campinas: Editora da Universidade Estadual de Campinas, 1994.

GIBBS, Jean Beverly. "Impressionism as a Literary Movement". The Modern Language Journal. Volume XXXVI. January, 1952 to December, 1952. p. 169-190

GONÇALVES, Denise Mafra. Adelino Magalhães e a consciência do instante. Dissertação de Mestrado. Universidade de Brasília, 1990. (in mimeo).

HABERMAS, Jürgen. O discurso filosófico da modernidade. Tradução de Maria Leopoldina de Almeida. Lisboa: Dom Quixote, 1998. 
HAUSER, Arnold. História Social da Literatura e da Arte. Tomo II. Tradução: Walter H. Geenen. São Paulo: Mestre Jou, 1972.

MAGALHÃES, Adelino. Obra Completa. Rio de Janeiro: Aguilar, 1963.

PLACER, Xavier. Adelino Magalhães e o Impressionismo na ficção. Rio de Janeiro: Livraria São José, 1962.

TEIXEIRA, Ivan. "Cem anos de Broquéis” In: CRUZ e SOUZA. Broquéis. São Paulo: Edusp, 1994. 